\title{
Nodulação e fixação de nitrogênio por forrageiras da caatinga cultivadas em solos do semiárido paraibano
}

\author{
Ana Dolores Santiago de Freitas ${ }^{1}$, Tácio Oliveira da Silva², Rômulo Simões Cezar Menezes ${ }^{3}$, \\ Everardo Valadares de Sá Barretto Sampaio ${ }^{3}$, Eduardo Rodrigues Araújo ${ }^{4}$, Vânia da Silva Fraga ${ }^{4}$ \\ 1 Universidade Federal Rural de Pernambuco, Departamento de Agronomia. Av. Dom Manoel de Medeiros, s/n, Recife, PE, 52171-900 \\ 2 Universidade Federal de Sergipe, Departamento de Engenharia Agronômica, São Cristóvão, SE, 49100-000. \\ 3 Universidade Federal de Pernambuco, Departamento de Energia Nuclear, Recife, PE, 50740-540. \\ 4 Universidade Federal da Paraíba, Departamento de Solos e Engenharia Rural, Areia, PB, 58397-000.
}

RESUMO - A fixação biológica de nitrogênio foi avaliada em jureminha (Desmanthus pernambucanus), orelha-de-onça (Macroptilium martii) e feijão-de-rolinha (Macroptilium lathyroides) cultivados em solos do semiárido da Paraíba, em vasos sem e com esterco bovino. Foram determinados o número e a biomassa de nódulos, os teores e as proporções de nitrogênio (N) fixado (percentual de nitrogênio da planta derivado do ar-\%Ndda), pelo método da abundância natural, utilizando-se o capim-buffel como planta controle. As leguminosas tiveram nodulação abundante, nos três solos e na ausência ou presença de esterco, salvo quando cultivadas em Neossolo Flúvico sem adubação. A adubação com esterco aumentou o número e a biomassa de nódulos. A fixação biológica de nitrogênio foi alta nas três espécies, nos três solos: na maioria das plantas, os valores superaram 50\%, chegando a 85\%. Esses dados permitem estimar a capacidade de fixação das espécies no campo em 10 a $30 \mathrm{~kg} \mathrm{ha}^{-1}$ de $\mathrm{N}$, considerando as densidades de plantio e produtividade usuais. As menores \%Ndda e quantidades fixadas foram encontradas nas plantas cultivadas em Neossolo Regolítico e aumentaram com a adição de esterco. Entre as espécies testadas, a fixação biológica de nitrogênio foi menos importante para D. pernambucanus. Nenhum dos parâmetros de nodulação avaliados (número, biomassa e biomassa/nódulo) explicou as proporções nem as quantidades de nitrogênio fixadas pelas plantas.

Palavras-chave: Desmanthus pernambucanus, leguminosa, Macroptilium lathyroides, Macroptilium martii, 15-N

\section{Nodulation and nitrogen fixation of caatinga forage species grown in soils of the semiarid area of Paraiba}

\begin{abstract}
The biological nitrogen fixation (BNF) of Desmanthus pernambucanus (pigeon bundleflower), Macroptilium martii and M. lathyroides (wild bushbean), grown in soils from the semiarid region of Paraíba, manured or not, was evaluated in a pot experiment. Nodule number and biomass, $\mathrm{N}$ content and the proportions of fixed $\mathrm{N}$ (\%Ndfa) were estimated, using the natural abundance methodology and buffel grass as a reference plant. The legume plants nodulated abundantly in all three soils, manured or not, except when grown in Fluvic Neosol without manure. The number and biomass of the nodules increased with manure. The BNF was high in all three species and soils: in most of the plants resulting in \%Ndfa above $50 \%$ and reaching $85 \%$. Using these data, a rough estimate of the fixation capacity of these species in the field indicates amounts of 10 to $30 \mathrm{~kg} \mathrm{ha}^{-1}$ of $\mathrm{N}$, taking planting and yielding usual densities. The lowest \%Ndfa and fixed quantities were obtained in plants growing in the Regolithic Neosol and they increased with manure application. Among the species, BNF was least important to $D$. pernambucanus. Neither the proportion nor the fixed quantities were explained by any of the nodule variables measured (number, biomass or biomass/nodule).
\end{abstract}

Key Words: Desmanthus pernambucanus, legume, Macroptilium lathyroides, Macroptilium martii, 15-N

\section{Introdução}

No semiárido brasileiro, a caatinga constitui a maior parte das pastagens usadas pelos rebanhos de bovinos, caprinos e ovinos, que respondem pelo maior valor da produção rural (Sampaio \& Menezes, 2002). Esta vegetação é rica em leguminosas (Queiroz, 2009), mas poucas foram estudadas quanto ao potencial produtivo e quase nenhuma quanto à sua capacidade de fixação biológica de nitrogênio - FBN (Teixeira et al., 2006; Freitas \& Sampaio, 2008).

A jureminha(Desmanthus pernambucanus (L.) Thell), o feijão-de-rolinha (Macroptilium lathyroides (L.) Urb.) e a orelha-de-onça (Macroptilium martii (Benth.) Marechal \& Baudet) são leguminosas forrageiras de porte herbáceo ou subarbustivo comuns na caatinga (Queiroz, 2009) e capazes de formar nódulos simbióticos (Allen \& Allen, 1981; 
Freitas \& Sampaio, 2008). Em experimento para avaliar a produção de biomassa e a nutrição mineral de forrageiras em solos característicos do semiárido, Araújo et al. (2011) observaram que essas leguminosas podem se beneficiar com a adubação com esterco, produzir maior quantidade de matéria seca e acumular mais nitrogênio que o capimbuffel. Ao cultivar leguminosas fixadoras e uma espécie não-leguminosa sob as mesmas condições, esse experimento gerou um material apropriado para estimar a fixação biológica de nitrogênio nas leguminosas comparando suas concentrações do isótopo ${ }^{15} \mathrm{~N}$ (Högberg, 1997).

A introdução de leguminosas fixadoras de nitrogênio em pastagens pode contribuir para o enriquecimento da forragem produzida, uma vez que normalmente essas espécies têm elevado teor de proteínas, bem como para melhoria da fertilidade dos solos, aumentando o rendimento de outras culturas. Em geral, os solos da região semiárida são pobres em nitrogênio e a utilização de fertilizantes químicos é inacessível à maioria dos agricultores, ficando os cultivos na dependência da mineralização da matéria orgânica.

Leguminosas nativas, adaptadas às condições de altas temperaturas e baixa disponibilidade de água do semiárido, podem ser capazes de crescer e, potencialmente, fixar nitrogênio com vantagem sobre outras espécies. Assim, neste trabalho foram avaliados alguns parâmetros da simbiose (nodulação, percentual de nitrogênio da planta derivado do ar (\%Ndda) e nitrogênio fixado na biomassa) nas plantas testadas previamente no experimento de Araújo et al. (2011).

\section{Material e Métodos}

O experimento foi conduzido em vasos, em casa-devegetação do Departamento de Solos e Engenharia Rural da Universidade Federal da Paraíba, em Areia, Paraíba. Utilizou-se um delineamento inteiramente casualizado com quatro repetições, seguindo um arranjo fatorial $3 \times 3 \times 2$, correspondendo a três espécies de leguminosas forrageiras (Desmantus pernambucanus (jureminha), Macroptilium lathyroides (feijão-de-rolinha) e Macroptilium martii (orelha-de-onça), três solos (Neossolo Flúvico, Neossolo Regolítico e Planossolo Háplico) e dois níveis de adubação com esterco bovino (sem adubação e $55 \mathrm{~g}$ de esterco por vaso, correspondendo a $20 \mathrm{Mg} \mathrm{ha}^{-1}$ ). Como planta controle não-fixadora, foi utilizado o capim-buffel (Cenchrus ciliaris L.), cultivado sob as mesmas condições e tratamentos das leguminosas.

Os solos foram coletados no semiárido da Paraíba, na camada de 0 a 0,2 m de profundidade. O Neossolo Flúvico foi coletado no município de Esperança (microrregião do Agreste), o Neossolo Regolítico no município de Areia (Brejo) e o Planossolo Háplico no município de Remígio (microrregião do Curimataú). Dos solos foram retiradas amostras para análises químico-físicas (Tabela 1).

Sementes das leguminosas e do capim-buffel, coletadas no município de Taperoá (PB), foram pré-germinadas em bandejas plásticas com areia lavada e as plântulas transplantadas para vasos de polietileno contendo $7 \mathrm{~kg}$ de solo, mantidos previamente a $50 \%$ da capacidade de campo, por um período de 15 dias para iniciar a mineralização dos nutrientes. Nos vasos com esterco, este foi misturado a uma profundidade de $15 \mathrm{~cm}$. As plantas foram desbastadas, deixando-se apenas uma plântula por vaso.

A colheita foi feita quando as plantas iniciaram a floração: aos 80 dias, para $D$. pernambucanus, e aos 90 dias, para M. martii e M. lathyroides. As plantas foram divididas em parte aérea e raízes e, dessas partes, foram coletados os nódulos, que foram contados e secos em estufa a $65^{\circ} \mathrm{C}$ para determinação da biomassa seca. Os resultados relativos ao número de nódulos por planta foram transformados em $(x+1)^{0,5}$. Na parte aérea, foram

Tabela 1 - Atributos químicos e físicos dos solos utilizados no ensaio, antes da aplicação do esterco

\begin{tabular}{|c|c|c|c|}
\hline Atributo & Neossolo Flúvico & Neossolo Regolítico & Planossolo Háplico \\
\hline pH em água $(1: 2,5)$ & 6,4 & 6,5 & 7,4 \\
\hline P-Mehlich-1 (mg dm $\left.{ }^{-3}\right)$ & 8,1 & 3,7 & 1,0 \\
\hline $\mathrm{K}^{+}-$Mehlich-1 (mg dm$\left.{ }^{-3}\right)$ & 33,8 & 140,4 & 23,4 \\
\hline $\mathrm{Mg}^{2+}-\mathrm{KCl} 1 \mathrm{~mol} \mathrm{~L}^{-1}\left(\mathrm{cmol}_{\mathrm{c}} \mathrm{dm}^{-3}\right)$ & 0,65 & 1,0 & 3,10 \\
\hline $\mathrm{Al}^{3+}-\mathrm{KCl} 1 \mathrm{~mol} \mathrm{~L}^{-1}\left(\mathrm{cmol}_{\mathrm{C}} \mathrm{dm}^{-3}\right)$ & 0,0 & 0,04 & 0,0 \\
\hline Soma de bases $\left(\mathrm{cmol}_{\mathrm{c}} \mathrm{dm}^{-3}\right)$ & 3,58 & 3,20 & 7,56 \\
\hline Carbono orgânico $\left(\mathrm{g} \mathrm{kg}^{-1}\right)^{1}$ & 13,7 & 5,67 & 13,7 \\
\hline Areia $\left(\mathrm{g} \mathrm{kg}^{-1}\right)^{2}$ & 657 & 805 & 686 \\
\hline Silte $\left(\mathrm{g} \mathrm{kg}^{-1}\right)^{2}$ & 114 & 110 & 209 \\
\hline Argila $\left(\mathrm{g} \mathrm{kg}^{-1}\right)^{2}$ & 229 & 85 & 105 \\
\hline
\end{tabular}

\footnotetext{
${ }^{1}$ Snyder \& Trofymow (1984).
}

2 Embrapa (1997). 
determinados os teores de ${ }^{15} \mathrm{~N}$, por espectrometria de massa e expressos em unidades de "delta”, que é o desvio por mil (\%) da abundância de ${ }^{15} \mathrm{~N}$ da amostra em relação ao padrão, no caso o $\mathrm{N}_{2}$ atmosférico:

$\delta=\left(\mathrm{R}_{\text {amostra }} / \mathrm{R}_{\text {padrão }}-1\right) \times 1000$, em que $\mathrm{R}_{\text {amostra }} \mathrm{e}$ $\mathrm{R}_{\text {padrão }}$ são as razões ${ }^{15} \mathrm{~N}:{ }^{14} \mathrm{~N}$ da amostra e do padrão $\left(\mathrm{N}_{2}\right.$ atmosférico), respectivamente.

Para estimar a fixação biológica do nitrogênio nas leguminosas estudadas, foi utilizado o método da abundância natural do ${ }^{15} \mathrm{~N}$. O percentual de nitrogênio da planta derivado do ar (\%Ndda) foi calculado utilizando-se a fórmula descrita por Shearer \& Kohl (1986):

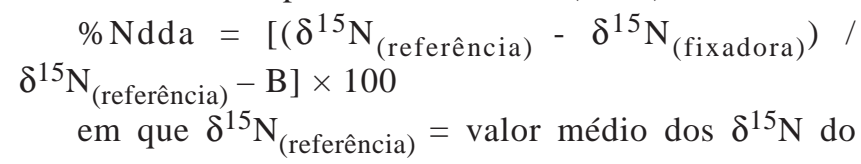
capim-buffel cultivado em cada solo, com e sem aplicação de esterco; $\delta^{15} \mathrm{~N}_{\text {(fixadora) }}=$ valor dos $\delta^{15} \mathrm{~N}$ de cada leguminosa em cada um dos vasos; e $\mathrm{B}=$ valor de $\delta^{15} \mathrm{~N}$ para plantas fixadoras cultivadas na ausência de nitrogênio. Como não existem dados sobre B para as espécies estudadas, foram utilizados os valores de 0 e de $-1,51 \%$, este último determinado para Vigna unguiculata (Nguluu et al., 2001).

A quantidade de nitrogênio fixado na parte aérea das plantas foi estimada multiplicando o valor de \%Ndda pelo conteúdo de nitrogênio de cada planta fixadora, obtido por Araújo et al. (2011) pelo produto do teor deste nutriente e da biomassa seca da parte aérea.

Os dados foram submetidos à análise da variância e as médias comparadas pelo teste Tukey a 5\% de probabilidade.

\section{Resultados e Discussão}

As três espécies de leguminosas tiveram nodulação abundante (Tabela 2) nos três solos, independentemente da aplicação de esterco, salvo quando cultivadas no Neossolo Flúvico sem adubação com esterco. A adubação com esterco aumentou o número de nódulos das três espécies neste solo (6 a 40 vezes) e no Neossolo Regolítico (3 a 9 vezes), no Planossolo Háplico, aumentou a nodulação apenas de $M$. martii (6 vezes). A nodulação natural (não induzida por estirpes de rizóbio inoculadas) é esperada em leguminosas cultivadas em solos do centro de diversidade da espécie (Bala et al., 2003). O tamanho desta população está relacionado a variações na nodulação (Abaidoo et al., 2007) e pode ser um bom indicador da eficiência relativa das populações de rizóbio (Thrall et al., 2007). D. pernambucanus, $M$. lathyroides e $M$. martii são das poucas espécies da caatinga com capacidade de nodulação conhecida (Allen \& Allen, 1981; Freitas \& Sampaio, 2008), mas pouco se sabe sobre as populações de bactérias capazes de formar simbiose com essas leguminosas nos solos nativos da região. Aparentemente, essas populações variam de tamanho de acordo com o solo e, na maioria dos casos, podem ser estimuladas pela adição de esterco.

As biomassas dos nódulos também responderam de forma diferenciada aos tipos de solo e à aplicação do esterco (Tabela 2). O padrão de resposta foi parecido com o de número de nódulos, mas as diferenças foram menores, pois os nódulos das plantas sem adubo tenderam a ser maiores, exceto no Planossolo Háplico.

Nódulos pequenos e não-funcionais representam um dreno de fotoassimilados (Atkins, 1984). Por isso, o número de nódulos pode ser uma variável que explica pouco a eficiência da simbiose. Em alguns casos, foram encontradas plantas com poucos nódulos e biomassa total bastante alta, ou seja, com nódulos bastante grandes. D. pernambucanus cultivada no Neossolo Flúvico sem esterco apresentou os maiores nódulos, apenas três com massa de $110 \mathrm{mg}$ (quase 37 mg nódulo ${ }^{-1}$ ). Nesse mesmo solo, com esterco, M. martii também apresentou biomassa específica de nódulos alta (10 mg nódulo ${ }^{-1}$ ). Nódulos com biomassa específica mais baixa foram obtidos para $D$. pernambucanus cultivada

Tabela 2 - Número e biomassa seca de nódulos de três leguminosas forrageiras nativas da caatinga, cultivadas em solos representativos do semiárido, sem ou com aplicação de esterco bovino, em quantidade equivalente a $20 \mathrm{Mg} \mathrm{ha}^{-1}$

\begin{tabular}{|c|c|c|c|c|c|c|}
\hline \multirow[t]{2}{*}{ Espécie } & \multicolumn{2}{|c|}{ Neossolo Flúvico } & \multicolumn{2}{|c|}{ Neossolo Regolítico } & \multicolumn{2}{|c|}{ Planossolo Háplico } \\
\hline & Sem esterco & Com esterco & Sem esterco & Com esterco & Sem esterco & Com esterco \\
\hline & \multicolumn{6}{|c|}{ Número de nódulos } \\
\hline Desmanthus pernambucanus & 3Ва & $127 \mathrm{Aa}$ & $72 \mathrm{Ba}$ & $222 \mathrm{Ab}$ & $19 \mathrm{Bb}$ & $114 \mathrm{Aa}$ \\
\hline Macroptilium martii & $4 \mathrm{Ba}$ & $23 \mathrm{Ab}$ & $44 \mathrm{Ba}$ & $136 \mathrm{Ab}$ & $132 \mathrm{Aa}$ & $129 \mathrm{Aa}$ \\
\hline \multirow[t]{2}{*}{ Macroptilium lathyroides } & $16 \mathrm{Ba}$ & $141 \mathrm{Aa}$ & 39Ва & 370Aa & $130 \mathrm{Aa}$ & $140 \mathrm{Aa}$ \\
\hline & \multicolumn{6}{|c|}{ Biomassa seca de nódulos (mg) } \\
\hline Desmanthus pernambucanus & $110 \mathrm{Ba}$ & $510 \mathrm{Aa}$ & $260 \mathrm{Aa}$ & $460 \mathrm{Ab}$ & $96 \mathrm{Bb}$ & $650 \mathrm{Aa}$ \\
\hline Macroptilium martii & $50 \mathrm{Aa}$ & $230 \mathrm{Aa}$ & $270 \mathrm{Aa}$ & 490Ab & 490Aа & $400 \mathrm{Aa}$ \\
\hline Macroptilium lathyroides & $120 \mathrm{Ba}$ & 570Aа & $250 \mathrm{Ba}$ & $1130 \mathrm{Aa}$ & 370Aab & 490 Аа \\
\hline
\end{tabular}

Médias seguidas pela mesma letra, minúscula na coluna entre as espécies vegetais e maiúscula na linha para as doses de esterco em cada solo não diferem entre si pelo teste de Tukey a $5 \%$ de probabilidade. 
no Neossolo Regolítico com esterco (2,1 mg nódulo-1) e $M$. lathyroides sem esterco no Planossolo Háplico (2,8 mg nódulo-1). Não foi identificado um padrão consistente para biomassa específica de nódulos entre as espécies com e sem adição de esterco.

Os valores de $\delta^{15} \mathrm{~N}$ médios nas folhas do capim buffel foram elevados para os três solos (8,97\% para o Neossolo Flúvico, 8,03\% para o Neossolo Regolítico e 9,95\% para o Planossolo Háplico) e não foram influenciados pela adição de esterco. Os sinais das leguminosas e do capim-buffel diferiram por mais de duas unidades de $\delta^{15} \mathrm{~N} \%$, permitindo segurança nas estimativas da fixação biológica de nitrogênio (Högberg, 1997). Esse padrão de composição isotópica de nitrogênio também foi encontrado por Freitas et al. (2010) em plantas arbóreas da caatinga. Nestas condições, o efeito da discriminação isotópica associada ao processo de fixação biológica do nitrogênio é muito pequeno, ou seja, o impacto de usar $\mathrm{B}=0$ ou $\mathrm{B}=-1,51 \%$ nas estimativas do $\%$ Ndda é de apenas poucas unidades percentuais. Por esta razão, para maior simplicidade, optou-se por apresentar apenas os resultados utilizando $B=-1,51 \%$ (Tabela 3 ), que são mais conservadores, possivelmente subestimando um pouco as quantidades de nitrogênio fixadas.

A fixação biológica de nitrogênio contribuiu com a nutrição nitrogenada das três espécies nos três solos e, na maioria dos casos, respondeu por proporções altas do nitrogênio das plantas (acima de 50\%), chegando, em alguns casos, a até mais de 85\% (Tabela 3). São contribuições significativas quando confrontadas com diversas estimativas apresentadas na literatura para leguminosas cultivadas, como soja (Oberson et al., 2007), feijão-caupi (Adjei-Nsiah et al., 2008), amendoim, fava e feijão (Herridge et al., 2008).
Feijão-caupi cultivado em Gana, por exemplo, utilizando a mesma metodologia $\left(\delta^{15} \mathrm{~N}\right)$ e valor B (-1,51\%o), teve valores de \%Ndda entre 46 e $79 \%$ (Adjei-Nsiah et al., 2008). Sabe-se que a fixação biológica de nitrogênio é um processo importante de aquisição desse mineral pelas espécies arbóreas nativas da caatinga, respondendo por até mais de 80\% do nitrogênio da planta (Freitas et al., 2010), mas não existem dados sobre sua importância para espécies herbáceas dessa formação vegetal.

Em geral, as plantas cultivadas com adição de esterco ao solo apresentaram maiores \%Ndda (média de 56\%) em comparação às cultivadas sem adubação (média de 42\%). Entre as espécies testadas, a fixação biológica de nitrogênio foi menos importante para a nutrição nitrogenada de D. pernambucanus, com média geral de 34\% de nitrogênio derivado da fixação biológica contra 55\% de $M$. martii e $60 \%$ de $M$. lathyroides. A proporção máxima de nitrogênio fixado em $D$. pernambucanus ficou em torno de $50 \%$ nas plantas adubadas e chegou a ser de apenas $6 \%$ no Neossolo Regolítico sem adubo. Apesar disso, quando cultivada em Neossolo Flúvico e Planossolo Háplico adubados com esterco, $D$. pernambucanus obteve mais que $50 \%$ do seu nitrogênio através da fixação biológica. Por outro lado, quando cultivadas em Neossolo Regolítico sem esterco, as três leguminosas tiveram menos de $20 \%$ de Ndda, reduzindo as médias gerais por espécie. Neste solo, apenas $M$. lathyroides com esterco apresentou alto (62\% de Ndda) desempenho. Já no Planossolo Háplico, a \%Ndda de D. pernambucanus foi, em média, apenas $20 \%$ da observada nas outras duas espécies. Neste solo e no Neossolo Flúvico, as \%Ndda de $M$. lathyroides variaram entre 53 e $75 \%$ e as de $M$. martii entre 57 e $86 \%$.

Tabela 3 - Quantidade de nitrogênio (N) total acumulado (mg planta ${ }^{-1}$ ), N derivado da atmosfera (\%Ndda) e $\mathrm{N}$ fixado (mg planta ${ }^{-1}$ ) na biomassa aérea de três leguminosas forrageiras, cultivadas em solos representativos do semiárido, sem ou com aplicação de esterco bovino, em quantidade equivalente a $20 \mathrm{Mg} \mathrm{ha}^{-1}$

\begin{tabular}{|c|c|c|c|c|c|c|}
\hline \multirow[t]{2}{*}{ Espécie } & \multicolumn{2}{|c|}{ Neossolo Flúvico } & \multicolumn{2}{|c|}{ Neossolo Regolítico } & \multicolumn{2}{|c|}{ Planossolo Háplico } \\
\hline & Sem esterco & Com esterco & Sem esterco & Com esterco & Sem esterco & Com esterco \\
\hline & \multicolumn{6}{|c|}{$\mathrm{N}$ total acumulado (mg planta $\left.{ }^{-1}\right)^{1}$} \\
\hline Macroptilium martii & $57 \mathrm{Ba}$ & $226 \mathrm{Aa}$ & 159Ba & $474 \mathrm{Aa}$ & 419Аа & $547 \mathrm{Aa}$ \\
\hline \multirow[t]{2}{*}{ Macroptilium lathyroides } & $19 \mathrm{Ba}$ & 345Aa & $141 \mathrm{Ba}$ & 390Aа & 329Bab & $547 \mathrm{Aa}$ \\
\hline & \multicolumn{6}{|c|}{ \%Ndda } \\
\hline \multirow[t]{2}{*}{ Macroptilium lathyroides } & $53,2 \mathrm{Aa}$ & 74,6 Aа & $19,3 \mathrm{Ba}$ & $62,5 \mathrm{Aa}$ & $72,8 \mathrm{Aa}$ & $60,6 \mathrm{Aa}$ \\
\hline & \multicolumn{6}{|c|}{$\mathrm{N}$ fixado (mg planta ${ }^{-1}$ ) } \\
\hline Desmanthus pernambucanus & $26 \mathrm{Aa}$ & $140 \mathrm{Aa}$ & $6 \mathrm{Aa}$ & $87 \mathrm{Ab}$ & $20 \mathrm{Ac}$ & 198Aa \\
\hline Macroptilium martii & $32 \mathrm{Ba}$ & $182 \mathrm{Aa}$ & $30 \mathrm{Aa}$ & $76 \mathrm{Ab}$ & 359Aа & 435 Aа \\
\hline Macroptilium lathyroides & $10 \mathrm{Ba}$ & $257 \mathrm{Aa}$ & $27 \mathrm{Ba}$ & $244 \mathrm{Aa}$ & $240 \mathrm{Ab}$ & 331Аа \\
\hline
\end{tabular}

${ }^{1}$ Araújo et al. (2011)

Médias seguidas pela mesma letra, minúscula na coluna entre as espécies vegetais e maiúscula na linha para as doses de esterco em cada solo não diferem entre si pelo teste Tukey a $5 \%$ de probabilidade. 
Nenhum dos parâmetros de nodulação avaliados (número, biomassa total e biomassa nódulo ${ }^{-1}$ ) explicou as proporções de nitrogênio fixado pelas plantas. As menores proporções de $\mathrm{N}$ fixado nas plantas no Neossolo Regolítico contrastam com seus maiores números de nódulos, indicando que boa parte dos nódulos não era efetiva. É possível que este solo muito arenoso tenha alguma deficiência de macro ou micronutriente requerido para o funcionamento adequado da simbiose, mas, dos nutrientes analisados, apenas o cálcio foi um pouco mais baixo que nos outros solos (Tabela 1). Exemplos da baixa correlação entre biomassas de nódulos e proporções de nitrogênio fixado são as \%Ndda de 41 a $56 \%$ obtidas com as baixas massas (50 a $120 \mathrm{mg}$ ) no Neossolo Flúvico sem adubação, comparadas às \%Ndda pouco maiores (60 a 79\%) obtidas com as biomassas de nódulos bem maiores (400 a 650 mg) no Planossolo Háplico adubado.

No Neossolo Flúvico sem esterco, D. pernambucanus produziu, em média, três nódulos com massa de $110 \mathrm{mg}$ (quase $37 \mathrm{mg}$ nódulo-1), no entanto, essa alta relação não refletiu em alta fixação (41,4 de \%Ndda e 31 mg de $\mathrm{N}$ fixado). M. martii, neste solo com adubo, também apresentou alta biomassa específica de nódulos (10 mg nódulo-1 ${ }^{-1}$, neste caso com altas \%Ndda ( $80,5 \%$ ) e quantidades de nitrogênio fixado (216 mg de $\mathrm{N} \mathrm{planta}^{-1}$ ). Entretanto, as quantidades de nitrogênio fixado não foram explicadas pela biomassa específica dos nódulos. A maior quantidade de nitrogênio fixado foi obtida para M. martii com adubo no Planossolo Háplico (375 mg) e a biomassa específica foi das mais baixas (3,10 mg nódulo $\left.^{-1}\right)$.

É importante destacar os efeitos que a adubação teve sobre a nodulação e a fixação de nitrogênio pelas três espécies estudadas, pois esse fato pode ter implicações importantes sobre o manejo dessas e de outras espécies quando cultivadas em campo. Uma vez que o crescimento vegetal na maioria dos solos da região semiárida é limitado pela disponibilidade de nitrogênio, a fixação biológica desse mineral é um processo que pode trazer ganhos significativos de produção a um custo relativamente baixo. Assim, práticas de manejo que potencializem esse processo, como a adubação com esterco, devem ser avaliadas com essa perspectiva. Sugere-se, portanto, a realização de estudos adicionais que identifiquem em detalhes os fatores que estimulam a fixação biológica de nitrogênio após a aplicação de esterco, como a adição de micronutrientes, entre outros fatores. Como o esterco é um recurso limitado na maioria das propriedades rurais do semiárido, também é importante determinar quais seriam as doses mínimas de esterco capazes de aumentar a \%Ndda por essas leguminosas.
Embora as proporções do nitrogênio da planta derivado da atmosfera indiquem a importância da fixação biológica de nitrogênio para sua nutrição, as quantidades desse nutriente fixado, que integram também a produção de biomassa e os teores de nitrogênio da planta, é uma medida mais direta da eficiência do processo, e um parâmetro de importância para plantas utilizadas como adubo verde.

Para as quantidades de nitrogênio fixadas simbioticamente, calculadas a partir dos dados de nitrogênio total acumulado na planta obtidos por Araújo et al. (2011), o padrão geral de resposta não diferiu muito do revelado pela \%Ndda, sendo as menores quantidades médias de nitrogênio fixadas por $D$. pernambucanus e maiores ( 2 a 28 vezes) nas plantas que receberam esterco (Tabela 3 ). Quando cultivada sem esterco, D. pernambucanus fixou apenas $7 \mathrm{mg}$ de nitrogênio por planta no Neossolo Regolítico, quantidade que atingiu 200 mg no Planossolo Háplico. Neste solo, as quantidades de nitrogênio fixadas nas leguminosas foram maiores, chegando a $431 \mathrm{mg}$ de nitrogênio por planta em $M$. martii. Comparando estas quantidades de nitrogênio fixadas com estimativas da literatura, pode-se considerar que as espécies estudadas têm bom potencial de fixação, apesar de cultivadas em vasos com apenas $7 \mathrm{~kg}$ de solo. Scheffer-Basso et al. (2001) obtiveram fixação média de 42,1 mg N planta ${ }^{-1}$ em Adesmia latifolia e 9,4 mg N planta ${ }^{-1}$ em Lotus corniculatus L. (leguminosas nativas do Sul do Brasil), em substrato estéril com solução nutritiva. Ndiaye et al. (2000) estimaram que o feijão-caupi chegou a fixar de 220 a $960 \mathrm{mg} \mathrm{N}$ planta $^{-1}$, mas em potes com $30 \mathrm{~kg}$ de solo que produziram mais de $40 \mathrm{~g}$ de biomassa seca por planta.

Da mesma forma que aconteceu para \%Ndda, nenhuma das variáveis de nodulação avaliadas (número, biomassa total e biomassa nódulo-1 ${ }^{-1}$ explicou as quantidades de nitrogênio fixadas, cujos valores variaram entre 0,027 e 0,939 mg de nitrogênio por mg de nódulo. As quantidades de nitrogênio fixadas por biomassa de nódulos são dados pouco referidos na literatura.

Estes dados permitem uma estimativa inicial da capacidade de fixação das espécies no campo, utilizando as quantidades de nitrogênio fixadas pelas leguminosas por vaso. Multiplicando-se essas quantidades por densidades usuais de plantio ou considerando produtividades de 1 a $2 \mathrm{Mg} \mathrm{ha}^{-1}$ de biomassa, com teores usuais de nitrogênio, as quantidades fixadas variam de 10 a $30 \mathrm{~kg} \mathrm{ha}^{-1}$ de $\mathrm{N}$. Obviamente, no campo, as condições são outras, com todas as possíveis limitações, principalmente de disponibilidade hídrica. Os números não devem ser tomados pelos seus valores absolutos, mas como um indicativo do potencial 
dessas plantas. São quantidades grandes, em relação aos teores de nitrogênio nos solos e às quantidades retiradas pelas culturas, e indicam a possível importância destas espécies em sistemas de produção do semiárido nordestino.

\section{Conclusões}

D. pernambucanus, M. martii e M. lathyroides possuem capacidade de nodular abundantemente em solos do semiárido, porém essa capacidade depende do tipo de solo. Essas três espécies apresentam alta capacidade de fixação biológica de nitrogênio (valores acima de 50\% na maioria das plantas), chegando, em alguns casos, a 85\% de nitrogênio derivado da atmosfera. No entanto, a fixação é menos importante para $D$. pernambucanus. Extrapolação da fixação para condições de campo indica valores entre 10 a $30 \mathrm{~kg} \mathrm{ha}^{-1}$ de nitrogênio. A adubação com esterco aumenta o número e a biomassa de nódulos, a proporção de nitrogênio derivado da atmosfera e as quantidades de nitrogênio fixado nas três espécies. Não há relação entre os parâmetros de nodulação (número, biomassa e biomassa/nódulo) e as proporções nem as quantidades de nitrogênio fixadas pelas plantas.

\section{Agradecimentos}

Ao CNPq (Projetos Imsear - Processo Edital MCT/ CNPq 01/2005. Demanda Induzida, Segmento 1 e Universal - Processo 476135/2008-7) e ao Inter American Institute for Global Change Research (CRN2-014) pelo apoio financeiro.

\section{Referências}

ABAIDOO, R.C.; KEYSER, H.H.; SINGLETON, P.W. et al. Population size, distribution, and symbiotic characteristics of indigenous Bradyrhizobium spp. that nodulate TGx soybean genotypes in Africa. Applied Soil Ecology, v.35, p.57-67, 2007.

ADJEI-NSIAH, S; KUYPER, TW; LEEUWIS, C. et al. Farmers' agronomic and social evaluation of productivity, yield and N-2fixation in different cowpea varieties and their subsequent residual $\mathrm{N}$ effects on a succeeding maize crop. Nutrient Cycling in Agroecosystems, v.80, p.199-209, 2008.

ALLEN, O.N.; ALLEN, E.K. The Leguminosae: a source book of characteristics use and nodulation. Wisconsin: University of Wisconsin Press, 1981. 812p.

ARAÚJO, E.R.; SILVA, T.O.; MENEZES, R.S.C. et al. Biomassa e nutrição mineral de forrageiras cultivadas em solos do semiárido adubados com esterco. Revista Brasileira de Engenharia Agrícola e Ambiental, v.15, p.890-895, 2011.

ATKINS, C.A. Efficiencies and inefficiencies in the legume/ Rhizobium symbiosis - a review. Plant and Soil, v.82, p.273-284, 1984.
BALA, A.; MURPHY, P.J.; OSUNDE, A.O. et al. Nodulation of tree legumes and the ecology of their native rhizobial populations in tropical soils. Applied Soil Ecology, v.2, p.211-223, 2003.

EMBRAPA BRASILEIRA DE PESQUISA AGROPECUÁRIA EMBRAPA. Serviço Nacional de Levantamento e Conservação de Solos. Manual de métodos de análise de solos. 2.ed. Rio de Janeiro: Embrapa, 1997. 212p.

FREITAS, A.D.S.; SAMPAIO, E.V.S.B. Fixação biológica do $\mathrm{N}_{2}$ em leguminosas arbóreas da Paraíba e de Pernambuco. In: MENEZES, R.S.C.; SAMPAIO, E.V.S.B.; SALCEDO, I.H. (Eds.) Fertilidade do solo e produção de biomassa no semi-árido. Recife: Editora UFPE, 2008. p.27-46.

FREITAS, A.D.S.; SAMPAIO, E.V.S.B.; FERNANDES, A.R. et al. Biological nitrogen fixation in legume trees of the Brazilian caatinga. Journal of Arid Environments, v.74, p.344-349, 2010.

HERRIDGE, D.F.; PEOPLES, M.B.; BODDEY, R.M. Global inputs of biological nitrogen fixation in agricultural systems. Plant Soil, v.311, p.1-18, 2008.

HÖGBERG, P. ${ }^{15} \mathrm{~N}$ natural abundance in soil-plant systems. New Phytologist, v.137, p.179-203, 1997.

NDIAYE, M.A.F.; SPENCER, M.M.; GUEYE, M. Genetic variability in dinitrogen fixation between cowpea (Vigna unguiculata (L.) Walp.) cultivars determined using the nitrogen-15 isotope dilution technique. Biology and Fertility of Soils, v.32, p.318-320, 2000.

NGULUU, S.N.; PROBERT, M.E.; McCOWN, R.L. et al. Isotopic discrimination associated with symbiotic nitrogen fixation in stylo (Stylosanthes hamata L.) and cowpea (Vigna unguiculata L.). Nutrient Cycling in Agroecosystems, v.62, p.10-13, 2002.

OBERSON, A.; NANZER, S.; BOSSHARD, C. et al. Symbiotic N-2 fixation by soybean in organic and conventional cropping systems estimated by $\mathrm{N}-15$ dilution and $\mathrm{N}-15$ natural abundance. Plant and Soil, v.290, p.69-83, 2007.

QUEIROZ, L.P. Leguminosas da caatinga. Feira de Santana: Universidade Estadual de Feira de Santana; Kew, Royal Botanic Gardens; Associação Plantas do Nordeste, 2009. 467p.

SAMPAIO, E.V.S.B.; MENEZES, R.S.C. Perspectivas de uso do solo no semi-árido nordestino. In: ARAÚJO, Q.R. (ED.) $\mathbf{5 0 0}$ anos de uso do solo no Brasil. Viçosa, MG: Sociedade Brasileira de Ciência do Solo, 2002. p.339-363.

SCHEFFER-BASSO, S.M.; VOSS, M.; JACQUES, A.V.A. Nodulação e fixação biológica de nitrogênio de Adesmia latifolia e Lotus corniculatus em vasos de Leonard. Revista Brasileira de Zootecnia, v.30, p.687-693, 2001.

SHEARER, G.; KOHL, D.H. $\mathrm{N}_{2}$-fixation in field settings: estimations based on natural ${ }^{15} \mathrm{~N}$ abundance. Australian Journal of Plant Physiology, v.13, p.699-756, 1986.

SNYDER, J.D.; TROFYMOW, J.A. A rapid accurate wet oxidation diffusion procedure for determining organic and inorganic carbon in plant and soil samples. Communications in Soil Science Plant Analysis, v.15, p.587-597, 1984.

TEIXEIRA, F.C.P.; REINERT, F.; RUMJANEK, N.G. et al. Quantification of the contribuition of biological nitrogen fixation to Cratylia mollis using the ${ }^{15} \mathrm{~N}$ natural abundance technique in the semi-arid caatinga region of Brazil. Soil Biology \& Biochemistry, v.38, p.1989-1993, 2006.

THRALL, P.H.; SLATTERY, J.F.; BROADHURST, L.M. et al. Geographic patterns of symbiont abundance and adaptation in native Australian Acacia-rhizobia interactions. Journal of Ecology, v.95, p.1110-1122, 2007. 